\title{
Computer Simulation of the Mass and Energy Balance during Gasification of Sugarcane Bagasse
}

\author{
Anthony Anukam, ${ }^{1,2}$ Sampson Mamphweli, ${ }^{1}$ Edson Meyer, ${ }^{1}$ and Omobola Okoh ${ }^{2}$ \\ ${ }^{1}$ Fort Hare Institute of Technology, University of Fort Hare, Private bag X1314, Alice 5700, South Africa \\ ${ }^{2}$ Department of Chemistry, University of Fort Hare, Private bag X1314, Alice 5700, South Africa \\ Correspondence should be addressed to Anthony Anukam; aanukam@ufh.ac.za
}

Received 28 August 2013; Revised 13 January 2014; Accepted 27 January 2014; Published 16 March 2014

Academic Editor: Ching Yuan Chang

Copyright (c) 2014 Anthony Anukam et al. This is an open access article distributed under the Creative Commons Attribution License, which permits unrestricted use, distribution, and reproduction in any medium, provided the original work is properly cited.

\begin{abstract}
This paper investigated the mass and energy balance of the gasification of sugarcane bagasse using computer simulation. The key parameters and gasifier operating conditions were investigated in order to establish their impact on gas volume and conversion efficiency of the gasification process. The heating value of sugarcane bagasse was measured and found to be $17.8 \mathrm{MJ} / \mathrm{kg}$ which was used during calculation of the conversion efficiency of the gasification process. Fuel properties and gasifier design parameters were found to have an impact on conversion efficiency of the gasification process of sugarcane bagasse. The moisture content of sugarcane bagasse was varied by $1.14 \%, 15 \%$, and $25 \%$, respectively. Optimum conversion efficiency was achieved at low moisture content (1.14\%) after computer simulation of the gasification process. The volume of carbon monoxide increased at low moisture content. It was also found that maximum conversion efficiency was achieved at reduced particle diameter $(6 \mathrm{~cm})$ and at reduced throat diameter $(10 \mathrm{~cm})$ and throat angle $\left(25^{\circ}\right)$, respectively, after these parameters were varied. Temperature of input air was also found to have an impact on the conversion efficiency of the gasification process as conversion efficiency increased slightly with increasing temperature of input air.
\end{abstract}

\section{Introduction}

Sugarcane bagasse is the residue that results from the crushing of sugarcane. It is generated in large quantities during the processing of sugarcane in the sugar industry. Sugarcane bagasse is mainly burnt inefficiently in boilers that provide the heating for the sugar industry thus the renewed interest in its efficient utilization through an efficient means of conversion such as gasification.

The gasification technology remains an old technology that has today reached an advanced stage and hence there is a huge expectation from user industries for its application [1]. Commercial fuels and chemicals have been produced in the past from gasification technologies and current developments show that the use of gasification technologies to produce syngas and other chemicals will continue to be on the rise [2]. For a country like South Africa with its vast agricultural residues such as sugarcane bagasse, it is imperative to have an efficient power generation system. Gasification of sugarcane bagasse is a carbon dioxide emission neutral source of energy and also has the advantage of syngas production. Another advantage of gasification of sugarcane bagasse is the potential to reduce storage and transport cost since the sugarcane bagasse can be used in the same place where is it generated. Gasification is an alternative energy conversion technology that converts biomass materials into energy. This process is achieved by reacting the material at high temperatures, usually above $1000^{\circ} \mathrm{C}$, in the presence of a limited amount of oxygen and/or steam. The resulting gas mixture is called producer gas, most commonly referred to as syngas with a heating value of $4-6 \mathrm{MJ} / \mathrm{kg}$. The syngas, when clean, can be used in stationary gas turbines and electricity generation or as a building block for a variety of chemicals and fuel. About $70-85 \%$ of the carbon in the feedstock is converted 
into the syngas and the ratio of carbon monoxide to hydrogen produced depends on the hydrogen and carbon content of the feedstock and the type of gasifier used. The syngas produced differs from natural gas in terms of heating value, composition, and flammability characteristics.

In the gasifier, the biomass material undergoes several different reaction processes including drying, distillation, oxidation, and reduction reaction processes. These reactions are as follows [3]:

$$
\begin{gathered}
2 \mathrm{C}+\mathrm{O}_{2} \longrightarrow 2 \mathrm{CO} \quad \text { (partial oxidation) } \\
\mathrm{C}+\mathrm{O}_{2} \longrightarrow \mathrm{CO}_{2} \quad \text { (complete oxidation) } \\
\mathrm{C}+2 \mathrm{H}_{2} \longrightarrow \mathrm{CH}_{4} \quad(\text { hydrogasification reaction) } \\
\mathrm{CO}+\mathrm{H}_{2} \mathrm{O} \longrightarrow \mathrm{CO}_{2}+\mathrm{H}_{2} \quad \text { (water-gas shift reaction) } \\
\mathrm{CH}_{4}+\mathrm{H}_{2} \mathrm{O} \longrightarrow \mathrm{CO}+3 \mathrm{H}_{2} \quad \text { (steam reforming reaction) } \\
\mathrm{C}+\mathrm{H}_{2} \mathrm{O} \longrightarrow \mathrm{CO}+\mathrm{H}_{2} \quad \text { (water-gas reaction) } \\
\mathrm{C}+\mathrm{CO}_{2} \longrightarrow 2 \mathrm{CO} \quad \text { (Boudourd reaction) }
\end{gathered}
$$

Equations (6) and (7) are the main reduction reactions and being endothermic have the capability to reduce the temperature of the syngas. The selection of gasification systems design and performance are influenced by the thermochemical characteristics of the biomass to be converted [4]. However, it is necessary to use fast and quick simulation techniques in order to efficiently utilize the energy resources. The key parameters that affect the performance of the gasifier are moisture content, throat angle, and throat diameter as well as diameter of the material under study and temperature of input air [5]. Little is known about these parameters and their impact on conversion efficiency of the gasification process. These parameters are the most critical operating parameters that affect gasifier performance and are useful empirical tools for scale-up designs of gasifiers $[5,6]$.

1.1. Principle of Operation of the Downdraft Gasifier. There are many types of gasifiers used in the gasification of biomass materials. However, the choice of gasifier type depends on the type of material to be gasified and end use of the gas produced. Fixed-bed downdraft or cocurrent gasifiers are relatively simpler to use; they are reliable and amenable to gasifier different kinds of feedstock and offer lower particulate concentration in product gases and can achieve higher efficiencies than other gasifiers. The downdraft gasifiers also have the advantage of the production of a gas with low tar content. Because of uneven heat distribution in the downdraft gasifier, it is only limited to small scale applications [7]. However, scale-up of the downdraft gasifier is possible if heat could be evenly distributed and cold spots avoided in the combustion zone of the gasifier since the generation of heat and the oxidation of condensable products from the distillation zone take place in the combustion zone. Figure 1 presents the main features of the downdraft gasifier.

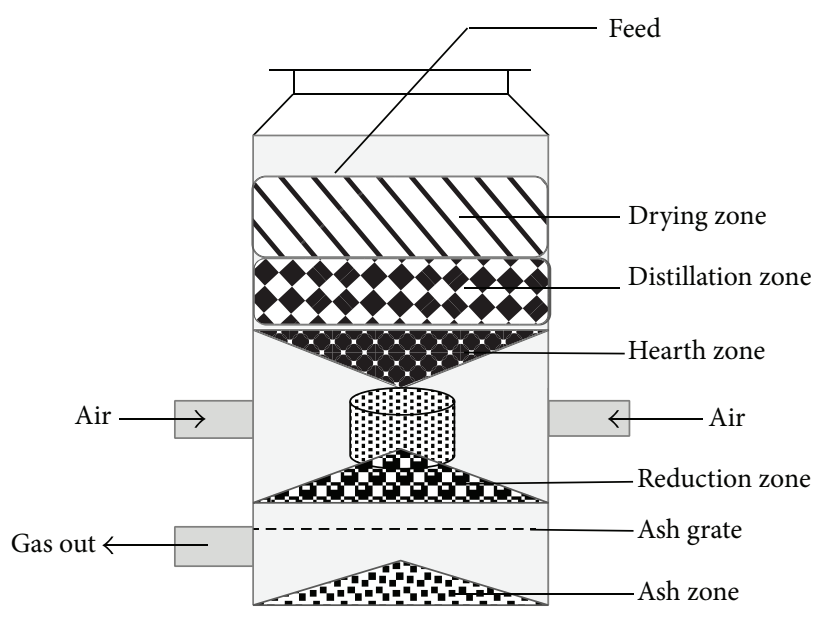

FIGURE 1: Fixed-bed downdraft gasifier or cocurrent gasifier [Adopted from FAO Corporate Document Repository, 1986] [30].

The biomass material is fed into the gasifier from the top of the gasifier and dried in the drying zone. Pyrolysis of the biomass takes place in the distillation zone where char and pyrolysis gases are formed. The drying zone and the distillation zone are mainly heated by radiation heat from the hearth (combustion) zone. In this zone, carbon dioxide and water vapour are formed. A part of the char formed in the distillation zone is also burnt in the hearth zone. Pyrolysis gases also pass through this zone and are burnt as well. The extent to which the pyrolysis gases are actually burnt depends on gasifier design, the biomass feedstock, and the skills of the operator. After oxidation of the feedstock in the hearth zone, the char left in the distillation zone and the combustion products (carbon dioxide and water vapour) in the hearth zone pass to the reduction zone where $\mathrm{CO}$ and $\mathrm{H}_{2}$ are formed. Traces of methane and other noncombustible gases are also formed in this zone.

\section{Materials and Method}

2.1. Proximate and Ultimate Analysis. The main by-product of the sugar industry in South Africa is sugarcane bagasse. It was chosen for this study because of its availability in excess of its usage. However, it is necessary to understand the composition of biomass before its application in energy conversion systems [1]. Proximate and ultimate analysis of biomass are usually used to describe the composition of biomass and different indicators are often used to quantify these components.

Samples of sugarcane bagasse were obtained from the Sugar Milling Research Institute in Durban, South Africa. It was received with over $50 \%$ moisture content. The sugarcane bagasse was air dried for 48 hours before analysis. The reason for predrying before analysis was to lower the moisture content of sugarcane bagasse so as to make it suitable for gasification operations because high moisture content will require more energy for gasification and will reduce the inside temperature of the gasifier as well as the heating value of the product gas. The dried sugarcane bagasse was milled to 
TABLE 1: Proximate and ultimate analysis of sugarcane bagasse.

\begin{tabular}{lc}
\hline Components & (\%) Composition \\
\hline Moisture content & 1.14 \\
Volatile matter content & 69.99 \\
Fixed carbon & 16.39 \\
Ash & 1.42 \\
\hline $\mathrm{N}$ & 0.20 \\
$\mathrm{C}$ & 44.1 \\
$\mathrm{H}$ & 5.7 \\
$\mathrm{~S}$ & 2.3 \\
$\mathrm{O}^{*}$ & 47.7 \\
\hline
\end{tabular}

* Obtained by difference.

size using a cryogenic grinder. The results of the proximate and ultimate analysis of sugarcane bagasse are presented in Table 1.

2.2. Energy Content of Sugarcane Bagasse. The standard measure of the energy content of a fuel is its heating value, also known as the calorific value. It indicates the energy available for conversion to useful energy. Fuel with high energy content is always better for gasification and most biomass materials have heating value in the range $10-20 \mathrm{MJ} / \mathrm{kg}$ [8]. The energy content of a fuel type can vary significantly depending on the climate and soil in which the fuel was grown as well as other conditions [9]. Biomass materials usually have low energy content because of high amount of oxygen in the biomass.

The heating value of sugarcane bagasse was determined by an oxygen bomb calorimeter (CAL2K model). The calorimeter was calibrated with $0.5 \mathrm{~g}$ of benzoic acid before measurements were taken. This was done under a pressurized oxygen environment of $3000 \mathrm{kpa}$.

2.3. Downdraft Gasifier Modeling. A DOS based downdraft gasifier modeling program developed by Jayah et al., 2003, was used to undertake computer simulation of the gasification process of sugarcane bagasse. This software is specifically designed for the simulation of the fixed-bed downdraft gasifiers. Table 2 presents the parameters used during gasification simulation.

Gas profiles were obtained from the simulation software program and these gas profiles were used to calculate the gas heating value from the percentage composition of the combustible gases in the syngas as follows [10]:

$\mathrm{HV}_{\text {gas }}$

$=\left(\frac{\left(\mathrm{CO}_{\mathrm{vol}} \times \mathrm{HVCO}\right)+\left(\mathrm{H}_{2 \mathrm{vol}} \times \mathrm{HVH}_{2}\right)+\left(\mathrm{CH}_{4 \mathrm{vol}} \times \mathrm{HVCH}_{4}\right)}{100 \%}\right)$,

where $\mathrm{HV}_{\text {gas }}$ is the gas heating value in $\mathrm{MJ} / \mathrm{kg}, \mathrm{CO}_{\mathrm{vol}}$ is the volume concentration of carbon monoxide gas in percentage, $\mathrm{HVCO}$ is the heating value of carbon monoxide gas (usually $12.64 \mathrm{MJ} / \mathrm{kg}$ by standard) [11], $\mathrm{H}_{2 \mathrm{vol}}$ is the volume concentration of hydrogen gas in percentage, $\mathrm{HVH}_{2}$ is the heating value of hydrogen gas $\left(10.1 \mathrm{MJ} / \mathrm{kg}\right.$ by standard) [12], $\mathrm{CH}_{4 \mathrm{vol}}$ is the volume concentration of methane gas in percentage, and $\mathrm{HVCH}_{4}$ is the heating value of methane gas $(38 \mathrm{MJ} / \mathrm{kg}$ by standard measurement) [11]. The heating value of the combustible gases was obtained from the standard gas table.

The conversion efficiency of the gasification process was determined after computer simulation by the following equation $[10]$ :

$$
\eta=\left[\left(\frac{\mathrm{HV}_{\text {gas }} \times 2}{\mathrm{HV}_{\text {fuel }}}\right) \times 100 \%\right],
$$

where $\eta$ is the efficiency of the gasifier, $\mathrm{HV}_{\text {gas }}$ the gas heating value, and $\mathrm{HV}_{\text {fuel }}$ the heating value of the fuel.

The computer software was basically a model developed for the downdraft wood gasifiers to study the effects of operating and design parameters on the performance of the gasifier [13]. It consists of two submodels, namely, flaming pyrolysis and gasification zone submodels. Flaming pyrolysis zone submodel is used to determine the product concentration and temperature of gas leaving the flaming pyrolysis zone. The gasification zone submodel is used to predict the output of the product gas and the length of the gasification zone at any given time [14]. The principle of mass and energy balance was also used.

2.3.1. Flaming Pyrolysis Zone Submodel. In the flaming pyrolysis zone, the general equation of reaction of the material can be expressed by

$$
\begin{gathered}
\mathrm{CH}_{a} \mathrm{O}_{b}+w \mathrm{H}_{2} \mathrm{O}+m\left(0.21 \mathrm{O}_{2}+0.79 \mathrm{~N}_{2}\right) \\
\longrightarrow x_{\text {char }} \mathrm{Char}+x_{\text {tar }} \mathrm{Tar}+x_{1} \mathrm{CO}+x_{2} \mathrm{H}_{2} \\
+x_{3} \mathrm{CO}_{2}+x_{5} \mathrm{CH}_{4}+x_{6} \mathrm{~N}_{2},
\end{gathered}
$$

where char was taken as carbon and ultimate analysis of tar as $\mathrm{CH}_{1.03} \mathrm{O}_{0.03}$ [15]. From (11) and (12) we can obtain the equilibrium equation and the corresponding equilibrium constant, respectively, as follows:

$$
\begin{gathered}
\mathrm{CO}+\mathrm{H}_{2} \mathrm{O} \longleftrightarrow \mathrm{CO}_{2}+\mathrm{H}_{2} \\
K_{3}=\frac{x_{3} \times x_{2}}{x_{1} \times x_{4}} .
\end{gathered}
$$

The correlation between the temperature and equilibrium constants for the above is given by [16]

$$
\begin{aligned}
\log \left(K_{3}\right)= & -36.72508+\frac{3994.704}{T}-4.46241 \\
& \times 10^{-3} T+6.71814 \times 10^{-7} T^{2}+12.2228 \log (T),
\end{aligned}
$$

where $T$ is the temperature (K).

By mass balance the following equation can be obtained:

$$
\text { Carbon: } 1=x_{\mathrm{char}}+x_{\mathrm{tar}}+x_{1}+x_{3}+x_{5} \text {, }
$$

Hydrogen: $a+2 w=1.03 x_{\mathrm{tar}}+2 x_{2}+x_{1}+2 x_{4}+4 x_{5}$,

$$
\text { Oxygen: } b+w+0.42 m=0.03 x_{\mathrm{tar}}+x_{1}+2 x_{3}+x_{4} \text {, }
$$


TABLE 2: Parameters used during gasification simulation.

\begin{tabular}{lclc}
\hline Fuel properties & Value & Gasifier operating conditions & Value \\
\hline Carbon $(\%)$ & 44.1 & Throat diameter $(\mathrm{cm})$ & 25.5 \\
Hydrogen $(\%)$ & 5.7 & Throat angle $\left(^{\circ}\right)$ & 30 \\
Oxygen $(\%)$ & 47.7 & Insulation thickness $(\mathrm{cm})$ & 17.5 \\
Nitrogen $(\%)$ & 0.20 & Thermal conductivity $(\mathrm{W} / \mathrm{cm} \mathrm{K})$ & 2.8 \\
Fixed carbon $(\%)$ & 18.19 & Temperature of input air $(\mathrm{K})$ & 300 \\
Bulk density $\left(\mathrm{g} / \mathrm{cm}^{3}\right)$ & 0.178 & Air input $(\mathrm{kg} / \mathrm{hr})$ & 44.5 \\
Diameter of SB particle $(\mathrm{cm})$ & 14.3 & Heat loss $(\%)$ & \\
Moisture content & $1.17(\%)$ & & 12.8 \\
\hline
\end{tabular}

The energy balance in flaming pyrolysis zone is given by

$$
\begin{aligned}
\mathrm{H}_{\mathrm{C}} \text { Wood }= & \mathrm{H}_{\mathrm{C}} \text { Char }+\mathrm{H}_{\mathrm{C}} \text { Tar }+\mathrm{H}_{\mathrm{C}} \mathrm{Gas} \\
& +\mathrm{H}_{\mathrm{S}} \text { Char }+\mathrm{H}_{\mathrm{S}} \text { Tar }+\mathrm{H}_{\mathrm{S}} \mathrm{Gas}+\text { Heatloss. }
\end{aligned}
$$

The number of moles of water $(w)$, including fuel moisture, air moisture, and water or steam addition can be calculated by the following equation [17].

Moisture in fuel $=$ dry matter in fuel $\times$ moisture content on dry basis

$$
w=(12 \times 1+1 \times a+16 \times b) \times \mathrm{mc}_{\mathrm{db}} \mathrm{kg} .
$$

The values of $a$ and $b$ have been given. Heat loss and $m$ (number of moles of oxygen input) are obtained from the experiment, $x_{5}, x_{\text {char }}$, and $x_{\text {tar }}$ are assumed, and $x_{1}, x_{2}, x_{3}, x_{4}$, $x_{6}$, and $T$ are solved by using the successive approximation method with a Fortran program. The higher heating values $(\mathrm{MJ} / \mathrm{kg})$ of bagasse, char, and tar are calculated from the equation as follows [18]:

$$
\mathrm{H}_{\mathrm{C}} \text { Wood }=0.3491 f_{\mathrm{C}}+0.1783 f_{\mathrm{H}}-0.1034 f_{\mathrm{O}}
$$

$\left(\mathrm{N}_{2}\right.$ and ash content are neglected),

$$
\begin{gathered}
\mathrm{H}_{\mathrm{C}} \text { Char }=0.3491 \times f_{\mathrm{C}, \mathrm{char}}, \\
\mathrm{H}_{\mathrm{C}} \text { Tar }=0.3491 \times f_{\mathrm{C}, \mathrm{tar}}+0.1783 f_{\mathrm{H}, \mathrm{tar}}-0.1034 f_{\mathrm{O}, \operatorname{tar}} .
\end{gathered}
$$

The chemical energy content of output gas, and sensible energy of char, tar, and output gases are calculated as follows:

$$
\begin{gathered}
\mathrm{H}_{\mathrm{C}} \mathrm{Gas}=241000 x_{1}+283000 x_{2}-802300 x_{5}, \\
\mathrm{H}_{\mathrm{S}} \text { Char }=12.15 x_{\mathrm{Char}} \times(T-300), \\
\mathrm{H}_{\mathrm{S}} \mathrm{Tar}=21.95 x_{\mathrm{tar}} \times(T-300), \\
\mathrm{H}_{\mathrm{S}} \mathrm{Gas}=x_{1} \mathrm{H}_{\mathrm{CO}}+x_{2} \mathrm{H}_{\mathrm{H}_{2}}+x_{3} \mathrm{H}_{\mathrm{CO}_{2}} \\
+x_{4} \mathrm{H}_{\mathrm{CO}_{2}}+x_{4} \mathrm{H}_{\mathrm{H}_{2} \mathrm{O}}+x_{5} \mathrm{H}_{\mathrm{CH}_{4}}+x_{6} \mathrm{H}_{\mathrm{N}_{2}} .
\end{gathered}
$$

2.3.2. Submodel of Gasification Zone. The gasification zone is modelled by following a particle along the axis of the reactor. The computer program has been formulated using Fortran language to calculate the characteristic profiles along the reactor axis. The profile includes temperature, concentrations, efficiency, and distance the particle travelled. The
TABLE 3: Measure of the energy content of sugarcane bagasse from this study and from previous authors.

\begin{tabular}{lc}
\hline Fuel (sugarcane bagasse) & Energy content (MJ/kg) \\
\hline Present study & 17.8 \\
Stanmore, 2010 [20] & 19 \\
Aboyade et al., 2013 [21] & 16.6 \\
Jenkins et al., 1998 [22] & $17.3-19.4$ \\
Jorapur and Rajvanshi, 1997 [23] & 18.1 \\
Demirel, 2012 [24] & $17-18$ \\
\hline
\end{tabular}

length coordinate is coupled with a time variable through the solid phase velocity. A small time increment approach is used in calculating the product composition of the zone. It involves the use of a step procedure starting from the gasification zone and marches axially through the reactor in appropriate time increments. The output values of the flaming pyrolysis zone are used as inputs for modelling the gasification zone [14].

\section{Results and Discussion}

3.1. Heating Value of Sugarcane Bagasse. Table 3 presents the measure of the energy content of sugarcane bagasse from this study and from previous authors. This was obtained after complete combustion of sugarcane bagasse to carbon dioxide and water vapour in an oxygen bomb calorimeter.

The heating value of sugarcane bagasse was measured and found to be $17.8 \mathrm{MJ} / \mathrm{kg}$ and the value is comparable to what is found in the literature as evident from Table 3. Conversion efficiency of the gasification process is based purely on this value. This value was used during calculation of the conversion efficiency of the gasifier after computer simulation of the gasification process.

3.2. Gasifier Simulation. A downdraft biomass gasification simulation software program developed by Jayah et al., 2003, described in Section 2.3 was used to undertake computer simulation of the gasification process of sugarcane bagasse. The initial parameters used for the gasification simulation process are presented in Table 2 in Section 2.3. However, these parameters were later varied in order to investigate their impact on conversion efficiency of the gasification process. Moisture content was also varied in order to investigate its impact as well not only on conversion efficiency of the 
TABLE 4: Parameters varied during gasification simulation.

\begin{tabular}{lc}
\hline Parameter & Range \\
\hline Moisture content $(\%)$ & $1.14,15,25$ \\
Diameter of SB particle $(\mathrm{cm})$ & $6,20,30$ \\
Temperature of input air $\left({ }^{\circ} \mathrm{C}\right)$ & $27,627,1227$ \\
Throat diameter $(\mathrm{cm})$ & $10,30,50$ \\
Throat angle $\left({ }^{\circ}\right)$ & $25,40,90$ \\
\hline
\end{tabular}

gasification process but also on gas volume. The parameters varied are presented in Table 4.

The parameters varied were particle diameter, throat diameter, and throat angle as well as temperature of input air and moisture content as evident in Table 4. Figures were played around with before finally establishing those figures that resulted in optimum conversion efficiency as well as those that lead to reduced conversion efficiency of the gasification process. Moisture content of 1.14\% (from the proximate analysis in Table 1) is as measured from the sample while $15 \%$ and $25 \%$ moisture contents were assumed based on the maximum allowable moisture content [19].

\subsubsection{Impact of Fuel Properties and Gasifier Operating Con-} ditions on Conversion Efficiency. The ratio of the products formed during gasification of biomass is influenced not only by the composition of the biomass but also by the operating conditions of the gasifier [8]. The heating value of sugarcane bagasse described in Section 2.1 was measured and found to be $17.8 \mathrm{MJ} / \mathrm{kg}$ and was used during calculation of the conversion efficiency of the gasification process. Timeconsuming gasification simulation was conducted to investigate the impact of fuel properties such as moisture content and particle diameter, and gasifier operating conditions such as throat angle and throat diameter as well as temperature of input air on the conversion efficiency of the gasification process of sugarcane bagasse. The impact of these fuel properties and gasifier operating conditions is described in this section.

Impact of Fuel Moisture Content on Gas Volume. The fuel properties and gasifier operating conditions presented in Table 1 were used to undertake computer simulation with only moisture content varied from $1.14 \%$ to $15 \%$ and $25 \%$, respectively. Figure 2 presents the impact of moisture content on gas volumes obtained after computer simulation of the gasification process of sugarcane bagasse using the gasifier operating parameters presented in Tables 2 and 4, respectively.

The major part of the syngas is formed through reduction reactions in the reduction zone of the gasifier most of which are endothermic reactions. The impact of moisture content on gas volumes is evident in Figure 2. The volume of carbon monoxide ( $\mathrm{CO}$ ) was found to be higher when the moisture content of sugarcane bagasse was low (1.14\%) compared to when it was higher (15\% and $25 \%$, resp.). This can be attributed to the fact that heat was not consumed during the drying of the feedstock; it was rather available for the reduction reactions to take place. The hydrogen $\left(\mathrm{H}_{2}\right)$ content

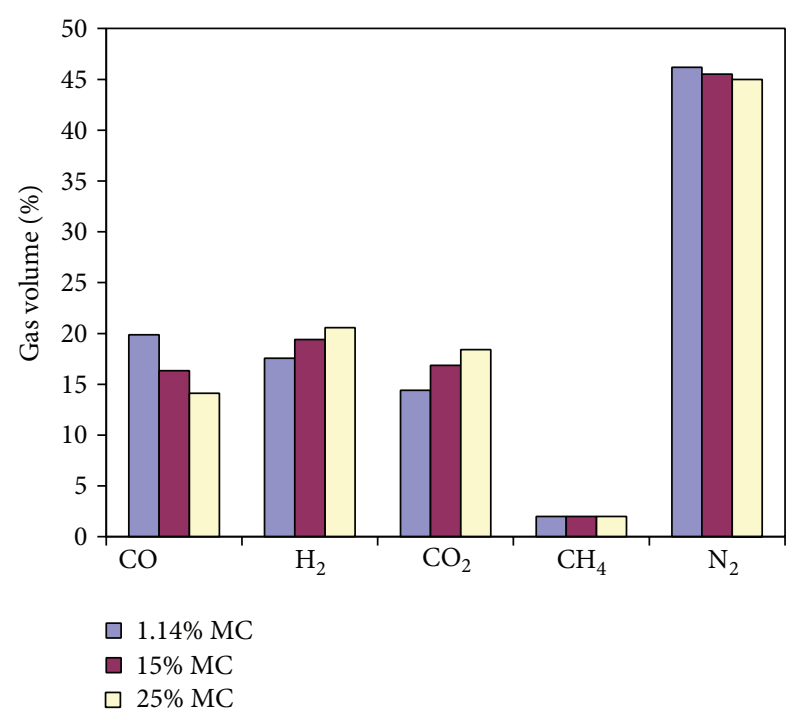

FIGURE 2: Gas volumes obtained through computer simulation.

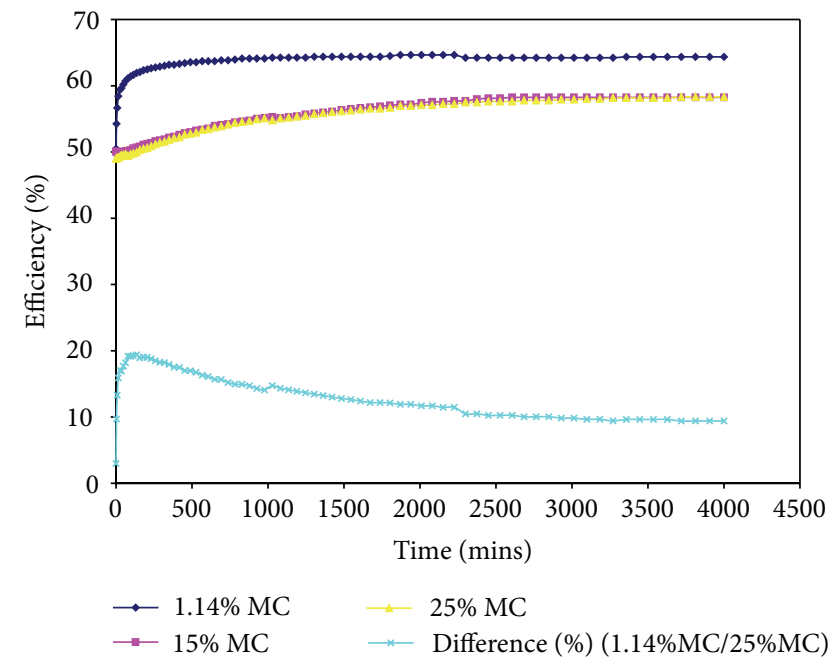

FIGURE 3: Simulated impact of moisture content on conversion efficiency.

of the syngas was found to be higher when the moisture content of sugarcane bagasse was assumed to be higher (15\% and $25 \%$, resp.). This is because of the availability of moisture for the water-gas reaction to take place.

Impact of Fuel Moisture Content on Conversion Efficiency. Moisture content is one important fuel property that governs gasifier design and also has an impact on conversion efficiency of the gasification process [1]. Figure 3 shows the impact of fuel moisture content on conversion efficiency. This was obtained after computer simulation of the gasification process using the parameters presented in Table 1. The moisture content was varied from $1.14 \%, 15 \%$, and $25 \%$, respectively as evident in Tables 2 and 4, respectively.

As moisture content increases, conversion efficiency decreases considerably as evident from Figure 3. Optimum conversion efficiency was achieved at low moisture content 
of $1.14 \%$. This observation can be explained by the reaction kinetics. As explained earlier in Section 1, the major part of the syngas is formed through reduction reactions. A high quantity of energy is consumed during the drying of the material in the drying zone of the gasifier and the energy is no longer available for the reduction reactions to take place. At higher moisture contents (15\% and 25\%, resp.), the low oxidation temperature inhibiting the rate of the reactions is compensated by a high water $\left(\mathrm{H}_{2} \mathrm{O}\right)$ concentration which accelerates the water-gas shift reaction (4) in Section 1. The percentage difference between $1.14 \%$ moisture content and $25 \%$ moisture content is approximately $20 \%$ in terms of efficiency. This value is significantly higher when compared to the percentage difference between $15 \%$ and $25 \%$ moisture contents.

The Impact of Particle Diameter on Conversion Efficiency. Particle diameter has an impact on the burning characteristics of the fuel because it affects the rate of heating and drying during gasification [9]. Figure 4 shows the impact of particle diameter on conversion efficiency of the gasification process of sugarcane bagasse obtained after computer simulation using the same parameters presented in Tables 2 and 4 , respectively. Only the particle diameter was varied between $6 \mathrm{~cm}, 20 \mathrm{~cm}$, and $30 \mathrm{~cm}$, respectively, while other parameters remained constant.

Conversion efficiency increases with decreasing particle diameter as evident in Figure 4. This is due to the fact that smaller particle diameters have larger surface area per unit mass and larger pore sizes which facilitates faster rates of heat transfer and gasification. Longer gasifier length is needed for large particle diameters to achieve optimum conversion efficiency [27].

The Impact of Temperature of Input Air on Conversion Efficiency. Gasifiers are generally operated at ambient air temperature of $27^{\circ} \mathrm{C}(300 \mathrm{~K})$. The gasification reactions explained in Section 1 occur simultaneously and the content and ratios of $\mathrm{CO}, \mathrm{H}_{2}$, and $\mathrm{CH}_{4}$ in the product gas are affected by temperature of the reactants $[3,28]$. Figure 5 presents the impact of temperature of input air on conversion efficiency. This was obtained after computer simulation of the gasification process using the parameters presented in Tables 2 and 4 with only temperature of input air varied between $27^{\circ} \mathrm{C}, 627^{\circ} \mathrm{C}$, and $1227^{\circ} \mathrm{C}$, respectively, while other parameters remained constant.

An experiment was conducted by Mathieu and Dubuisson, 2002, to investigate the impact of temperature of input air on gasifier conversion efficiency. They found that reaction temperature increased when the temperature of input air was increased. As noticed from Figure 5, conversion efficiency increases slightly as temperature of input air increases. This observation is due to heat brought into the reactants which induces an increase in reaction temperature. The production of $\mathrm{CH}_{4}$ in the reactions explained earlier decreases when reaction temperature, and hence temperature of input air, increases. The production of carbon monoxide (CO) increases at the expense of carbon and carbon dioxide when temperature increases $[25,29]$.

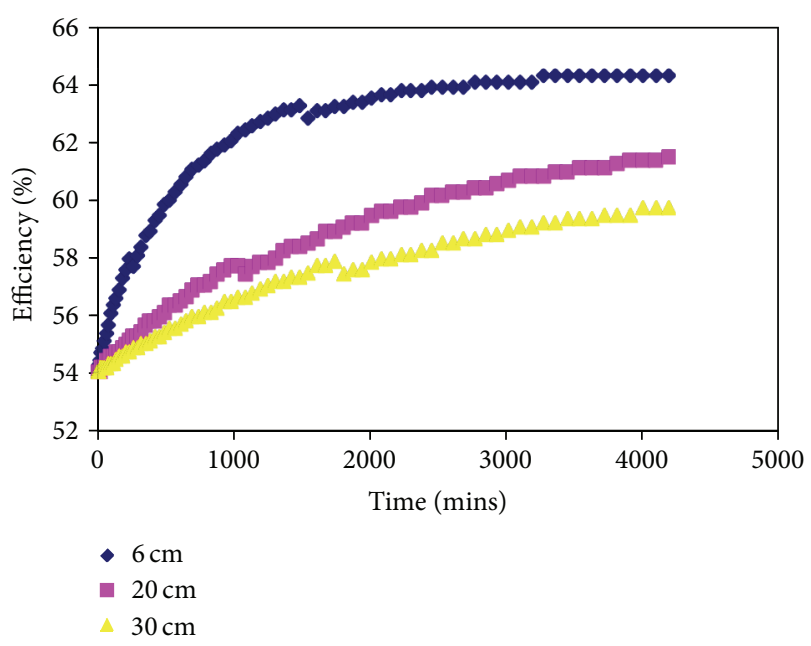

Figure 4: Impact of particle diameter on conversion efficiency.

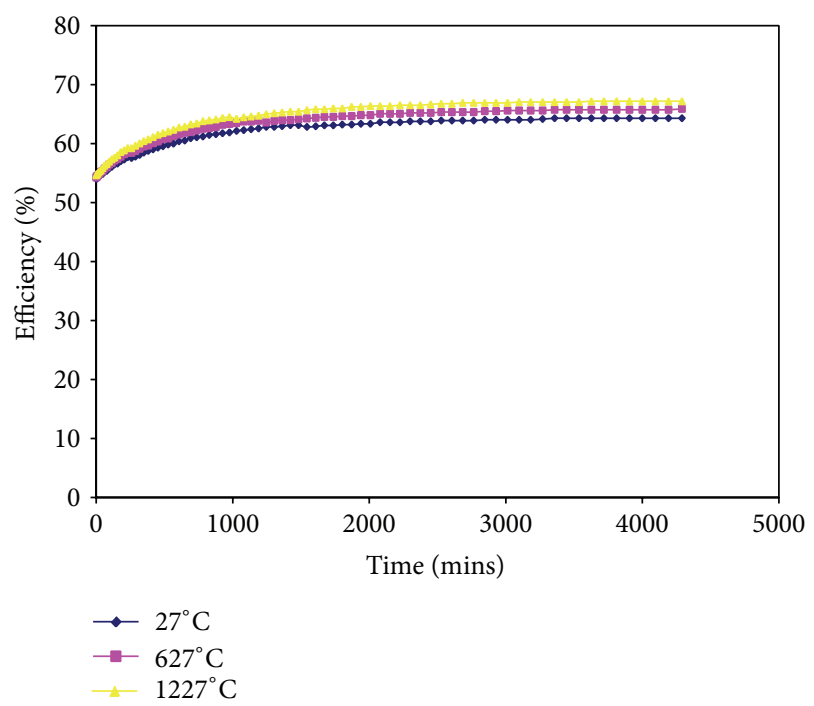

FIGURE 5: Impact of temperature of input air on conversion efficiency.

The Impact of Throat Diameter on Conversion Efficiency. The main purpose of the throat in a downdraft gasifier is to distribute heat evenly around the combustion zone and consequently along the gasification axis. This heat distribution is important for optimum conversion efficiency [19]. Figure 6 shows the impact of throat diameter on conversion efficiency. This was obtained after computer simulation of the gasification process using the parameters presented in Tables 2 and 4 with only the throat diameter varied between $10 \mathrm{~cm}$, $30 \mathrm{~cm}$, and $50 \mathrm{~cm}$, respectively. Other parameters remained constant.

The smaller the throat diameter the more efficient the gasification process as evident in Figure 6 . Whereas larger throat diameters $(30 \mathrm{~cm}$ and $50 \mathrm{~cm}$, resp.) result in lower conversion efficiency, smaller throat diameters $(10 \mathrm{~cm})$ increase conversion efficiency. This is because larger throat diameters 
TABLE 5: A comparison of the simulated results from this study with experimental data from the literature.

\begin{tabular}{|c|c|c|c|}
\hline & Parameter & Range & Conversion efficiency (\%) \\
\hline \multirow{15}{*}{ This study } & \multirow{3}{*}{ Moisture content } & $1.14 \%$ & 66 \\
\hline & & $15 \%$ & 58 \\
\hline & & $25 \%$ & 50 \\
\hline & \multirow{3}{*}{ Particle diameter } & $6 \mathrm{~cm}$ & 65 \\
\hline & & $20 \mathrm{~cm}$ & 58 \\
\hline & & $30 \mathrm{~cm}$ & 51 \\
\hline & \multirow{3}{*}{ Temperature of input air } & $27^{\circ} \mathrm{C}$ & 57 \\
\hline & & $627^{\circ} \mathrm{C}$ & 59 \\
\hline & & $1227^{\circ} \mathrm{C}$ & 61 \\
\hline & \multirow{3}{*}{ Throat diameter } & $10 \mathrm{~cm}$ & 65 \\
\hline & & $30 \mathrm{~cm}$ & 62 \\
\hline & & $50 \mathrm{~cm}$ & 58 \\
\hline & \multirow{3}{*}{ Throat angle } & $25^{\circ}$ & 65 \\
\hline & & $40^{\circ}$ & 62 \\
\hline & & $90^{\circ}$ & 57 \\
\hline Mamphweli, 2010 [19] & Moisture content & $15 \%$ & 73 \\
\hline Basu et al., 2009 [25] & Particle diameter & $250-1500 \mu \mathrm{m}$ & $72-85$ \\
\hline Basu et al., 2009 [25] & Temperature of input air & $400-680^{\circ} \mathrm{C}$ & $60-70$ \\
\hline \multirow{3}{*}{ Gunarathne et al., 2013 [26] } & \multirow{3}{*}{ Throat diameter } & $125 \mathrm{~mm}$ & 71.66 \\
\hline & & $150 \mathrm{~mm}$ & 72.79 \\
\hline & & $175 \mathrm{~mm}$ & 72.66 \\
\hline
\end{tabular}

decrease temperature due to divergent effect and hence the rate of the gasification reaction. Even though smaller throat diameters increase conversion efficiency, longer gasification period is required to achieve that efficiency [1].

The Impact of Throat Angle on Conversion Efficiency. Throat angle is a special unique feature of the downdraft gasifier and its impact on conversion efficiency is important [1]. Figure 7 presents the impact of throat angle on conversion efficiency at 25,40 , and 90 degrees, respectively, also obtained through computer simulation of the gasification process using the parameters presented in Tables 2 and 4. Only the throat angle was varied while other parameters remained constant.

Smaller throat angles $\left(25^{\circ}\right)$ tend to result in higher conversion efficiency as evident in Figure 6 whereas larger throat angles $\left(40^{\circ}\right.$ and $\left.90^{\circ}\right)$ decrease conversion efficiency because the latter decrease the temperature of the gasification reaction due to divergent effect. Although smaller throat angle increases efficiency, it also requires longer gasification period to achieve maximum conversion efficiency [1].

\subsection{Comparison with Experimental Data Based on Litera-} ture. The study, though, did not look at experimental data; however, a comparison between the simulated process studied and experimental data based on literature has been undertaken. Table 5 presents a comparison of the parameters considered for optimum gasification efficiency between simulated data from this study and experimental data from previous authors.

The simulation results agree well with the experimental data found in the literature as evident in Table 5 and are useful

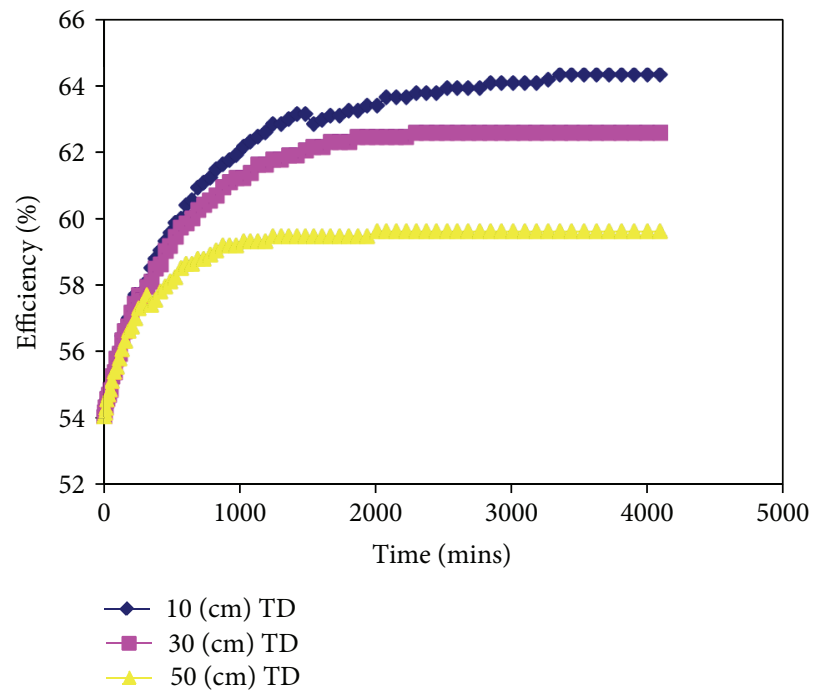

Figure 6: The impact of throat diameter on conversion efficiency.

to understand the processes reproducing the experimental data.

\section{Conclusion}

Computer simulation of a downdraft biomass gasifier was performed on sugarcane bagasse and results showed that several characteristics affect the gasification process and performance of sugarcane bagasse including moisture content and particle diameter as well as gasifier operating parameters 


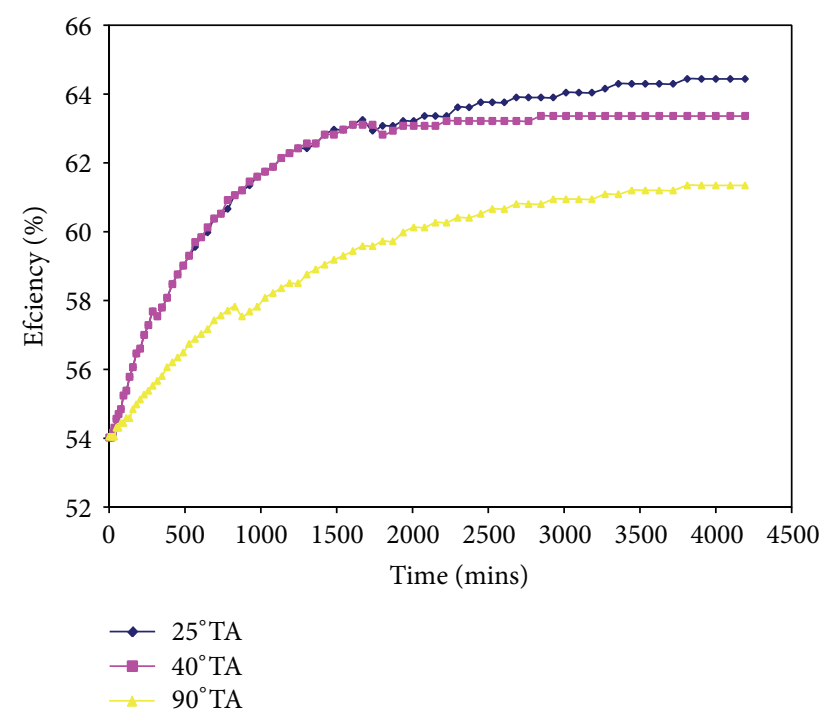

Figure 7: The impact of throat angle on conversion efficiency.

such as throat angle, throat diameter, and temperature of input air. Results also showed that these parameters are quite interrelated. Gasification rate, process efficiency, and gas heating value are affected by each of these parameters. Gas volume increased at reduced moisture content and the gas heating value is largely influenced by the volume of combustible gases in the syngas which in turn influences the conversion efficiency of the gasification process. It was also found that conversion efficiency is enhanced at low moisture content. Conversion efficiency also increased slightly with increasing temperature of input air due to additional enthalpy needed for reaction to occur. Reduced throat angle and throat diameter also enhanced the conversion efficiency of the gasification process. The study finally established that a laboratory scale as well as a large scale gasifier with enhanced conversion efficiency can be designed using simulation results.

\section{Conflict of Interests}

The authors declare that there is no conflict of interests regarding the publication of this paper.

\section{Acknowledgments}

This research was supported by the Fort Hare Institute of Technology, University of Fort Hare and Eskom as well as the National Research Foundation and Govan Mbeki Research and Development Centre in form of funding provided and their support is gratefully acknowledged.

\section{References}

[1] S. S. Kumar, K. Pitchandi, and E. Natarajan, "Modeling and simulation of down draft wood gasifier," Journal of Applied Sciences, vol. 8, no. 2, pp. 271-279, 2008.
[2] S. Sadaka, Book chapter on Gasification. Associate Scientist, Center for Sustainable Environmental Technologies and Adjunct Assistant Professor, Department of Agricultural and Biosystems Engineering Iowa State University, 2002.

[3] A. Kumar, D. D. Jones, and M. A. Hanna, "Thermochemical biomass gasification: a review of the current status of the technology," Energies, vol. 2, no. 3, pp. 556-581, 2009.

[4] P. Iyer, T. Rao, P. Groover, and N. Singh, Biomass-Thermochemical Characterization, Chemical Engineering Department, Indian Institute of Technology, Delhi, India, 2002.

[5] T. Reed and A. Das, Handbook of Biomass Downdraft Gasifier Engine System, SERI, Golden, Colo, USA, 1988.

[6] J. Perez, O. Diaz, R. Obando, and A. Molina, "Design methodology of a pilot-scale downdraft fixed bed biomass gasifier," Rev Technologicas, no. 22, pp. 121-140, 2009.

[7] Solar Energy Research Institute, Handbook of Biomass Downdraft Gasifier Engine Systems, 1988.

[8] T. Chandrakant, Biomass Gasification-Technology and Utilization, Humanity Development Library. Artes Institute, Glucksburg, Germany, 2002, http://www.pssurvival.com/.

[9] D. Ciolkosz, Characteristics of Biomass as a Heating Fuel. Renewable and Alternative Energy Fact Sheet, Penn State College of Agricultural Sciences. Agricultural Research and Coorporative Extension, 2010, http://www.energy.extension.psu.edu/.

[10] S. Mamphweli, Implementation of a 150 KVA biomass gasifier system for community economic empowerment in South Africa [Ph.D. thesis], University of Fort Hare, 2009.

[11] D. Bjerketvedt, J. R. Bakke, and K. Van Wingerden, "Gas explosion handbook," Journal of Hazardous Materials, vol. 52, no. 1, pp. 1-150, 1997.

[12] M. Fossum and R. Beyer, Co-Combustion: Biomass Fuel Gas and Natural Gas, SINTEF Energy Research, Trondheim, Norway, 1998.

[13] J. Chen, Kinetic Engineering Modeling of Co-Current Moving Bed Gasification Reactors For Carbonaceous Material, Cornell University, New York, NY, USA, 1986.

[14] T. Jayah, Evaluation of a Downdraft Wood Gasifier for Tea Manufacturing in Sri Lanka, Melbourne University, Victoria, Australia, 2002.

[15] T. N. Adams, "A simple fuel bed model for predicting particulate emissions from a wood-waste boiler," Combustion and Flame, vol. 39, no. 3, pp. 225-239, 1980.

[16] W. Gumz, Gas Producers and Blast Furnaces, Theory and Method of Calculation, John Wiley \& Sons, New York, NY, USA, 1950.

[17] J. Chen, Kinetic engineering modelling of co-current moving bed gasification reactors for carbonaceous material [Ph.D. thesis], Cornell University, New York, NY, USA, 1987.

[18] S. Gaur and T. Reed, Thermal Data For Natural and Synthetic Fuels, Marcel Dekker, New York, NY, USA, 1998.

[19] S. Mamphweli, "Physics 505 lecture notes," University of Fort Hare, Alice, South Africa. Unpublished lecture notes, 2010.

[20] B. R. Stanmore, "Generation of energy from sugarcane bagasse by thermal treatment," Waste and Biomass Valorization, vol. 1, no. 1, pp. 77-89, 2010.

[21] A. Aboyade, J. Görgens, M. Carrier, E. Meyer, and J. Knoetze, "Thermogravimetric study of the pyrolysis characteristics and kinetics of coal blends with corn and sugarcane residues," Fuel Processing Technology, vol. 106, pp. 310-320, 2013.

[22] B. Jenkins, L. Baxter, T. Miles Jr., and T. Miles, "Combustion properties of biomass," Fuel Processing Technology, vol. 54, no. 1-3, pp. 17-46, 1998. 
[23] R. Jorapur and A. Rajvanshi, "Sugarcane leaf-bagasse gasifiers for industrial heating applications," Biomass and Bioenergy, vol. 13, no. 3, pp. 141-146, 1997.

[24] Y. Demirel, "Energy and Energy types," in Energy, Green Energy and Technology, pp. 27-70, Springer, London, UK, 2012.

[25] P. Basu, M. Vichuda, and M. A. Leon, "Gasification of rice husk in supercritical water," in Proceedings of the 8th World Conference on Chemical Engineering, paper \# 971, p. 520, Montreal, Canada, August 2009.

[26] D. Gunarathne, S. Jatunarachchi, S. Senanayake, and B. Wei, "The effect of throat diameter on the performance of a downdraft biomass gasifier," International Journal of Energy Engineering, no. 3, pp. 171-175, 2013.

[27] V. Kirubakaran, V. Sivaramakrishnan, R. Nalini, T. Sekar, M. Premalatha, and P. Subramanian, "A review on gasification of biomass," Renewable and Sustainable Energy Reviews, vol. 13, no. 1, pp. 179-186, 2009.

[28] T. H. Jayah, L. Aye, R. J. Fuller, and D. F. Stewart, "Computer simulation of a downdraft wood gasifier for tea drying," Biomass and Bioenergy, vol. 25, no. 4, pp. 459-469, 2003.

[29] P. Mathieu and R. Dubuisson, "Performance analysis of a biomass gasifier," Energy Conversion and Management, vol. 43, no. 9-12, pp. 1291-1299, 2002.

[30] FAO Corporate Document Repository, "Wood gas and engine fuel," 1986, http://www.fao.org/docrep/t0512e/t0512e0a.htm. 


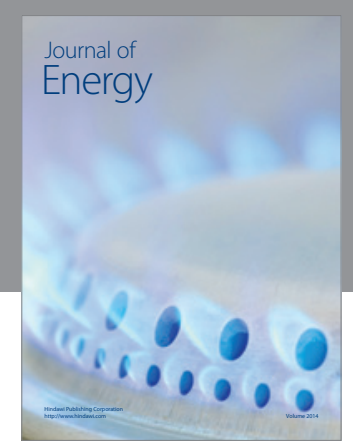

Journal of

Industrial Engineering
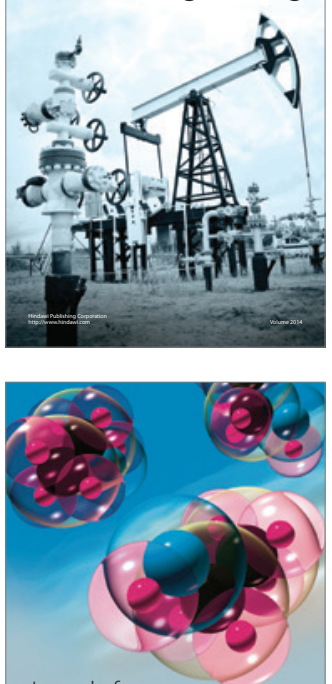

Fuels
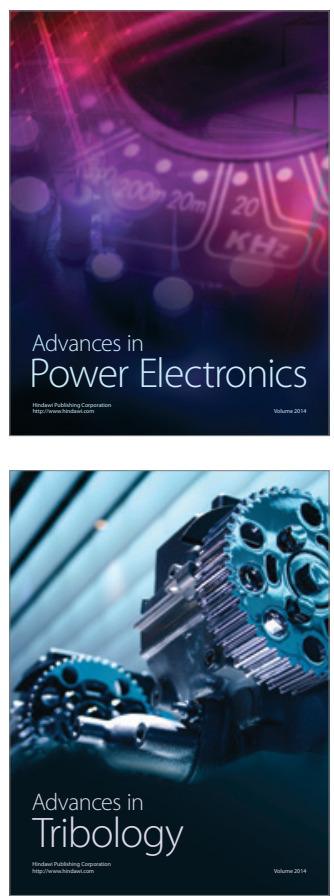

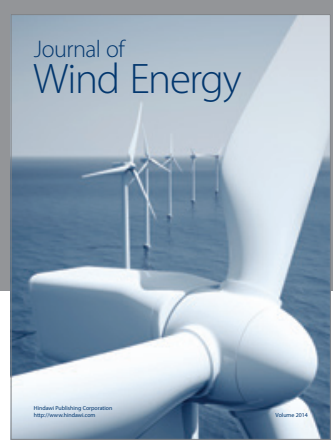

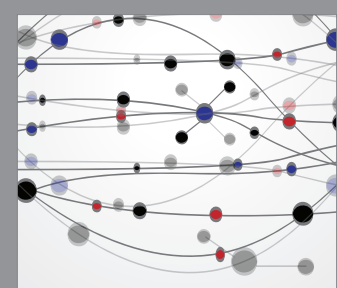

The Scientific World Journal

Submit your manuscripts at http://www.hindawi.com

Journal of

Structures
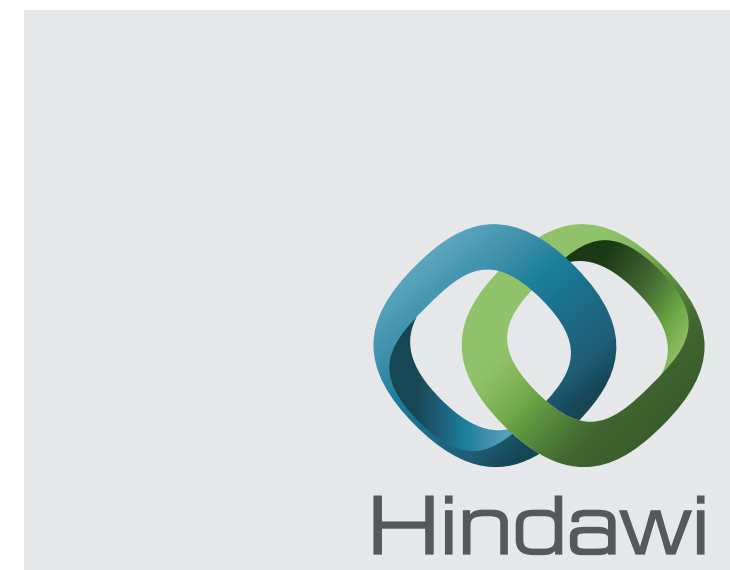

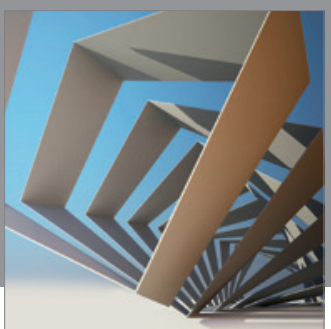

Rotating

Machinery
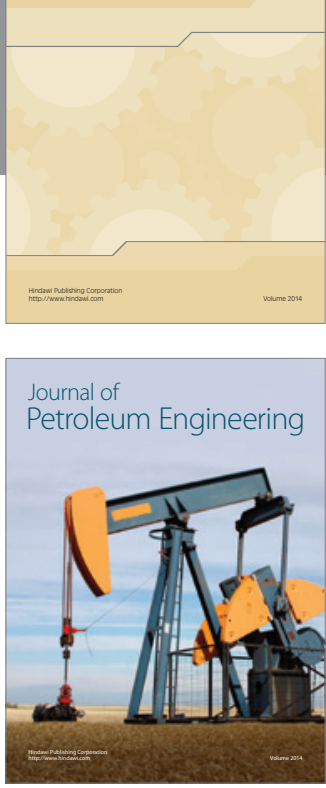

Journal of

Solar Energy
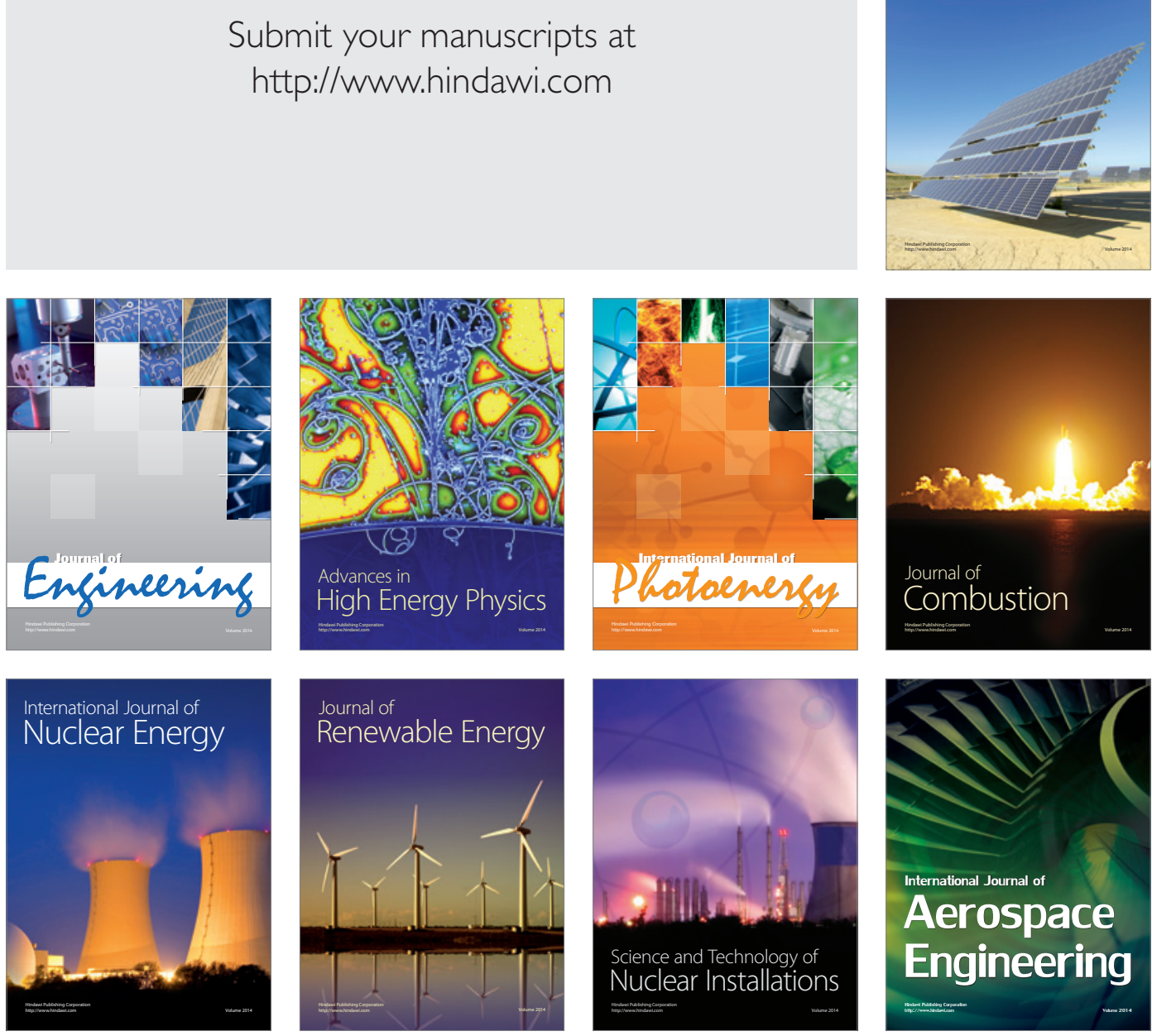